\title{
Thinking on the Countermeasures of Ecological Tourism Management in Nature Reserve
}

\author{
Jinyin Xiong \\ Xichang University, Xichang, Sichuan 615013, China.
}

Keywords: nature reserve; Ecotourism; Countermeasures; thinking.

\begin{abstract}
Ecotourism contributes to the coordinated development of economy and environment. Nature reserve is an important site to the develop ecological tourism, because the original, natural and protective features of its resources. In China, some state-owned nature reserves have been developed for ecological tourism. This process resulting in environmental problems in nature reserves, because of lack of proper management. Therefore, in order to ensure the harmonious development of ecological tourism in nature reserves, it is very necessary to improve and regulate the tourism management in nature reverses.
\end{abstract}

\section{Introduction}

Ecotourism management is a service that is closely related to tourism development, mainly including consumption, tourism and management protection. Now domestic tourism is developing rapidly and ecotourism management is improving gradually. But not enough, nature reserve is a very important tourism resource, we must strengthen the management of tourism, protect the natural landscape and achieve sustainable development.

\section{The Problems of Ecological Tourism Management in Nature Reserves.}

\subsection{Managers Don't Have an Accurate Understanding of Ecotourism.}

At this stage, the concept of ecotourism has become a hot topic, but only a few people know the true meaning of ecotourism development. Many people's understanding of ecotourism is to travel through the natural environment. Although the form is similar, ecotourism is different from natural tourism. Eco-tourism concern more about how to protect the natural environment. While developing tourism economy, ecotourism pays more attention to the dissemination and education of environmental knowledge to tourists. So far, there are still some people believe that ecotourism does not have any influence on the environment in nature reserves. Influenced by this erroneous concept, many nature reserves managers have strengthened the development of ecological tourism. They blindly developed ecotourism projects without enough consideration about the characteristics of resources. What's worse, some ecotourism managers view the destruction of precious natural resources as the inevitable price of economic benefits. Under the influence of erroneous concept, these managers destroyed the natural environment and affected the sustainable development of nature reserves.

\subsection{Lack of Professional Human Resources}

Nature reserve management organization plays a very important role in the management of the ecological tourism activities. nature reserve management level is a key factor that affect the sustainable development of ecological tourism. Management ability is mainly reflected in the personnel quality of managers. If the management ability of the management is not good enough, it will be detrimental to the development and management of ecotourism, while at the same time, it will have an important impact on the sustainable development of nature reserves. When managers have the knowledge of tourism, ecology, forestry, environment and other aspects, they can control impact that the tourism behavior on ecosystem and wild animals, make effective management decisions, which could build an scientific system of the nature reserve ecotourism. In contrast, biodiversity in nature reserves may be destroyed, resulting in a lack of stability and even environmental degradation. At present, the level of managerial personnel in nature reserves is relatively low. Most of the managers 
are high school graduates with less than half of the ecological management personnel with a bachelor's degree or above. Some of the reserves are managed by researchers, but they are only conducting scientific research and cannot effectively manage ecotourism in nature reserves. Most of the reserve management personnel lack of the knowledge that related with ecology and environment, has not participated in professional training activities. The lack of professional management talent hindered the development of nature reserve ecotourism.

There is no reasonable control over the number of tourists.

In the nature reserve that develop eco-tourism, we can always see the fact that the number of tourists exceeds the environmental capacity of the nature reserve. Due to the lack of tourism management experience, some nature reserves have not reasonably forecast and analyzed the environmental capacity in nature reserves during the development of tourism. They tend to focus only on how to attract tourists and pursuit economic benefits while ignoring environmental protection. During the peak season, there are a lot of tourists in nature reserves, which have adverse effects on wildlife, vegetation and ecological environment in the reserve. Therefore, it is necessary to control the number of tourists.

\subsection{The Economic Benefits Did Not Meet the Expected Goals.}

Many nature reserves have developed the ecotourism. however, these activities did not bring great economic benefits, at the same time, the economic benefit were not used effectively to protect nature reserve environment. Some nature reserves economic returns is very low, and even appear to be unable to make ends meet. Some nature reserve ecotourism is guided by government or the nature of the enterprise, won the good economic benefit, but they did not put the profits into the protection of nature reserve funds. The vigorous development of ecotourism brings a lot of negative effects, but the managers does not use the profits to protect the nature reserve and cannot effectively maintain the sustainable development of the ecosystem. Affected by this problem, A lot nature reserve where developed ecotourism can not handle the balance of economic develop and environment protection. Some of them could not even make the ends meet.

\section{Current Analysis.}

China has the characteristics of rich land resources and diversified tourism landscape. $40 \%$ of those are the cultural landscape and $60 \%$ of those are the natural landscape. The protection of natural landscape is the basic condition for the sustainable development of tourism industry in China. At present, $60.13 \%$ of the nature reserve in our country have started ecotourism management work, including the environmental management of the reserve, the construction of the ecological recovery, coordination of nature reserve and the construction of the regional service management, etc., this will help the planning of social resources and economic development in our country. However, because our country started very late in the management of ecotourism in nature reserves, it has periodic characteristics, such as insufficient management funds and relative lack of personnel in management. Therefore, it is necessary to study the countermeasures of ecotourism management in nature reserves.

\section{Optimization Strategies for Ecological Tourism Management in Nature Reserves.}

\subsection{Use Scientific Method}

The key to how to scientifically manage ecological tourism in nature reserve is to adopt effective strategies to deal with the ecological management in nature reserve. For example, We should consider the ecological development of nature reserve status quo during develop ecotourism, using the measures such as ecological development and tourism projects to the environment protection is analyzed, and the development of ecotourism in nature reserves, to the rationalization of the difficulties, but also in the practice of constructing scientific system, thus forming a comprehensive development management structure. For example, in the process of developing nature reserves in the eastern part of China, we use network procedures, implement system analysis, and carry out digital development, management and monitoring. 
Use digital program for early warning, the nature reserve, the weather such as rain and hail, the first time will protect nature reserve plan for managers, help to ecological tourism management in the process of management work has the support of the data, ensure the nature reserves in the process of development of scientific and orderly.

\subsection{Carry out Macro Management and Make Clear Management Responsibilities.}

The implementation of macro management requires the formulation of relevant laws. Ecotourism management cannot be implemented without legal support, therefore, to use compulsory legal system on nature reserve with constraints on the development work is the basic condition to ensure that promote the development of reserve trend is correct. At present, our country issued $<$ the measures for the administration of the Marine nature reserve of the republic of China $>,<$ regulations on the administration of nature reserves $>$, but we still need the relevant departments' supplement. Ecotourism management approach involves different aspects of tourism management, legal system is the direction of the development of the tourism management, at the same time, to formulate measures for the management of the process, but also in nature reserve management system and responsibility mechanism and coordination mechanism in construction.

In addition, we need clear management responsibilities. We should conduct a unified management of the nature reserve for the establishment of a tourism management agency, which should have departments in charge of forestry, agriculture and so on. In addition, to ensure the stable operation of the management mechanism, it is necessary to cooperate with other organizations, such as the joint management and supervision of non-governmental organizations and local communities, etc.

\subsection{Increase the Investment in Ecological Management.}

The ecological tourism management in nature reserves needs to be carried out continuously. Meanwhile, it is necessary to solve the problem of capital shortage and strengthen the management and increase the investment of ecotourism in nature reserves. We can be realized through the following two ways: one is that countries should strengthen the management of ecotourism in nature reserves and increase economic investment, plan the fund of ecotourism reasonably, do a good job in the tourism development of modern society and the protection of the ecological tourism work, reduce the funding pressure in the process of development and protection of natural resources, made the ecological economy develop sustainably. Second, we will increase our attention to the management of ecotourism in nature reserves, and we can use the investment methods of tourism projects to increase investment in this issue. For example, the construction of scenic spots and recreation facilities and the protection and investment of natural environment are closely connected. We need to adopt innovative approaches to resolve conflicts between the development of eco-tourism projects and the protection of nature reserves.

\subsection{Strengthen the Management of Tourists.}

One is to control the number of tourists, ensure the reasonable number of tourists during the peak season, and avoid the problem of resource waste in the off-season. For example, in the weekends, summer and winter vacation, holiday time, managers could limit the number of vehicles or the number of tickets, etc., In the off-season, managers can provide a free shuttle service and the way of lower fares, and so on; The second is to standardize tourists' behaviors, strengthen the education for tourists, and conduct some environment-friendly activities, so that tourists can participate actively in the activities and then learn to travel environment friendly.

\subsection{Formulate the Goal Concept of Long-Term Development.}

To comprehensively promote the development of the ecotourism in nature reserve management, we need to set up a long-term development goals, forming a systematic resource control consciousness, make the development of new working structure. If a region is implementing management policy that really put protecting environment in systematic development plan, the environmental restoration work will be able to push forward. The effects can reflect not only in that dividing the natural protection zone into primary and secondary protection, but also in creating specific management strategies for different nature reserveand test the quarterly to the environment. The management of eco-tourism is conducive to our sustainable development. 


\section{Conclusion}

In a word, the management of ecological tourism in nature reserves is worth thinking about, it is conducive to the sustainable development of our society and environment. Under the premise of serious thinking, we can organize the concept of sustainable development, effectively manage ecological tourism in nature reserve, obtain economic benefits and protect the natural environment at the same time. Therefore, it is imperative to study the management measures of ecotourism in nature reserves, which is an effective way for new industries to realize economic benefits and social benefits.

\section{Acknowledgments}

The "Thirteenth Five-Year Plan" of Social Sciences Research in Sichuan Province in 2017: "Exploration and practice of tourism poverty alleviation in Liangshan Yi District"(SC17XK051).

\section{References}

[1]. of tan jing ". Nature reserve ecotourism management countermeasure thinking [J/OL]. And innovation of science and technology, 2018 (8) [2018-04-02]. http://kns.cnki.net/kcms/detail/14.1369.N.20180312.1133.004.html.

[2]. liu ting. Study on the community participation model of tourism development in eco-fragile regions [D]. Southwest jiaotong university,2016.

[3]. Chen lu. Research on ecological tourism management in nature reserve [D]. Nanjing forestry university,2015.

[4]. xin xuhui. Research on economic development of hulunbeier ecotourism [D]. Central university of nationalities, 2013.

[5]. jungle. Research on tourism ecology of the national nature reserve of daqinggou [D]. Beijing forestry university,2013. 